\title{
Estudo da especificidade a açucares e avaliação das atividades anti-inflamatórias e antinocepitvas da lectina de sementes de Chenopodium quinoa
}

\author{
Ferreira, E.A.M. ${ }^{1}$, Pompeu, D.G. ${ }^{1 *}$, Godin, A.M. ${ }^{2}$, Machado, R.R. ${ }^{2}$, \\ Gonçalves, D.B. ${ }^{1}$, Silva, J.A ${ }^{1}$, Granjeiro, P.A. ${ }^{1}$ \\ ${ }^{1}$ Curso de Bioquímica, Universidade Federal de São João Del-Rei, Divinópolis/MG \\ ${ }^{2}$ Departamento de Farmacologia, Universidade Federal de Minas Gerais, Belo Horizonte/MG \\ *e-mail: daviagp@yahoo.com.br
}

\section{Resumo}

Lectinas de plantas são glicoproteínas que se ligam especificamente a determinados açúcares. Essa ligação ocorre de maneira reversível e, através dela, as lectinas são capazes de exercer e desencadear diversas atividades biológicas, como antitumoral, bioinseticida, antimicrobiana e anti ou próinflamatórias. Lectinas já se mostraram capazes de agir tanto de forma próinflamatória como também anti-inflamatória, sendo esta atividade determinada por diversos fatores como por exemplo a composição e estrutura proteica, sua especificidade a açúcares, sua concentração e vias de administração. O objetivo deste trabalho é analisar a especificidade da lectina purificada de sementes de Chenopodium quinoa (CqLec) contra diversos tipos de açúcares, simples e complexos, utilizando os grupos sanguíneos A, B e AB, e avaliar seu potencial anti-inflamatório e antinoceptivo. Foram testados, através do teste de inibição da atividade hemaglutinante, 16 açúcares entre monossacarídeos, dissacarídeos e polissacarídeos, homo e heterosacarídeos, dos quais não foi encontrada especificidade para $\mathrm{CqLec}$,. No teste da atividade antiinflamatória, foram testadas 3 concentrações de CqLec $(0,1 ; 1,0$ e 10,0mg/Kg) e foi encontrado que $\mathrm{CqLec}$ apresenta uma boa atividade anti-inflamatória inibindo o edema de pata induzido por carragenina em mais de $50 \%$ já na concentração $0,1 \mathrm{mg} / \mathrm{Kg}$ no tempo de 1 hora. Para avaliação da atividade antinoceptiva,, foram realizados os testes de placa quente e formalina e, em ambos, a presença de CqLec não aumentou a tolerância dos camundongos aos estímulos noceptivos em ambos os testes. Podemos concluir que CqLec possui 
atividade anti-inflamatória, porém não possui atividade antinoceptiva e que, esta proteína não possui afinidade para os açúcares testados.

Palavras-chave: Chenopodium quinoa, lectina, especificidade, antiinflamatório, noceptivo

Apoio financeiro: CNPq, FAPEMIG, UFSJ 